\title{
83rd Annual Meeting of the Swiss Society for Dermatology and Venereology
}

September 27-29, 2001, Geneva

Editor: Prof. J .-H. Saurat

Contents

Monoclonal Rearrangement of the T Cell Receptor GammaChain in Lichenoid Pigmented Purpuric Dermatitis of Gougerot-Blum Responding to Topical Corticosteroid Therapy P. Lor, U. Krueger, W. Kempf, G. Burg, F.O. Nestle

Periorbital Oedema and Erythema as a Manifestation of Discoid Lupus erythematosus R.P. Braun, L.E. French, I. Massouyé, J.-H. Saurat

Papular Elastorrhexis.

Report of Five Cases

S.A. Buechner, P. Itin

Survey of Dermatophyte Infections in the Lausanne Area (Switzerland)

M. Monod, S. J accoud, C. Zaugg,

B. Léchenne, F. Baudraz, R. Panizzon . 201
Eosinophilic Fasciitis

(Shulman Syndrome)

S. Mosconi, M. Streit, M. Brönimann,

L.R. Braathen ............ 204

Cutaneous Larva migrans

Associated with Löffler's

Syndrome

N.A. Schaub, A.P. Perruchoud,

S.A. Buechner

Multiple Hyperkeratotic

Spicules and Myeloma

R.P. Braun, A.M. Skaria, J .-H. Saurat,

L. Borradori

Generalised Pustular Psoriasis Induced by Cyclosporin A Withdrawal Responding to the Tumour Necrosis Factor Alpha Inhibitor Etanercept

J . Kamarashev, P. Lor, A. Forster,

L. Heinzerling, G. Burg, F.O. Nestle . 213

\section{KARGER}

(C) 2002 S. Karger AG, Basel

Fax + 41613061234

E-Mail karger@karger.ch

www. karger.com
Accessible online at:

www. karger.com/journals/drm 